\title{
Influence of microwave on chromium complex composition in tanning liquor
}

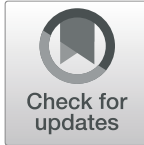

Jinwei Zhang ${ }^{1,2}$, Wuyong Chen ${ }^{1,2^{*}}$ and Carmen Gaidau ${ }^{3^{*}}$

\begin{abstract}
Since microwave irradiation could promote hydrolysis and olation of chromium tanning liquor, but the influence of microwave on chromium complex component in the liquor was still unknown. Chromium sulphate solution (0\% basicity) and 33\% basicity chromium tanning liquor were subjected microwave (MW) and water bath (WB) heating, and the samples without any warming were regarded as control. Ion exchange chromatography (IEC) and gel filtration chromatography (GFC) were used to measure the charge composition and molecular size of chromium complexes in each sample. FT-IR was used to characterize the structure of chromium complexes in each composition separated by IEC. Moreover, the chromium tanning liquor after warming was used in hide powder tanning trials to illustrate whether microwave would affect its tanning ability. The results show there are more high positive charge and large molecular size complexes in chromium tanning liquor after warming but the phenomena are more significant in MW samples compared with WB due to non-thermal effect of microwave. In addition, microwave has more powerful effect on 33\% basicity chromium tanning liquor hydrolysis and olation to generate larger molecular size complexes. In FT-IR results, the combination pattern between chromium and ligands are changed after warming but there is no difference between WB and MW. The chromium exhaustion and thermal stability of hide powder tanned with chromium tanning liquor after microwave irradiation are both higher. It could conclude that both thermal and non-thermal effects of microwave promote the process together, and the nonthermal effect leads to more high positive charge and large molecular size complexes and has stronger influence on high polarity system. In short, this work would provide theoretical basis for applying microwave in tanning agent modification and chrome tanning process further.
\end{abstract}

Keywords: Microwave, Chromium tanning liquor, Chromium complex, lon exchange chromatography, Gel filtration chromatography

\section{Introduction}

Microwave lies between radio wave and infrared frequency with wavelengths from $1 \mathrm{~mm}$ to $1 \mathrm{~m}$ and has been widely used in chemical synthesis for several decades [1, 2]. Microwave has been known to offer faster, simpler, and more cost-effective processes and result in high-yield, high-purity products and mild reaction condition [3, 4]. As these advantages, more and more

\footnotetext{
* Correspondence: wuyong.chen@163.com; carmen_gaidau@hotmail.com 'Key Laboratory of Leather Chemistry and Engineering of Ministry of Education, Sichuan University, Chengdu 610065, China

${ }^{3}$ R\&D National institute for Textile and Leather-Division Leather and Footwear Research Institute, 031215 Bucharest, Romania

Full list of author information is available at the end of the article
}

leather technologists and chemists pay attention to applying microwave in leather manufacturing, such as dyeing, drying, tanning and so on [5]. During the processes, it could be found that microwave always has positive effect on promoting the combination between collagen and chemicals. For example, the leather had better color fastness when microwave was used in dyeing [6]; the fat uniformity in leather was better with microwaveassisting fatliquoring [7]; enzyme unharing and bating were more effective under microwave [8]; leather dried under microwave usually had higher thermal stability [9].

Raw hides and skin will not convert into leather without tanning, in which chrome tanning is dominant 
because leather tanned by the method has brilliant hydrothermal stability, excellent mechanical properties and outstanding durability. Not surprisingly, microwave also strengthens and enhances the combination between collagen and tanning agent and leads to better tanning effect and efficiency. In vegetable tanning, the shrinkage temperature (Ts) of leather tanned under microwave was $1{ }^{\circ} \mathrm{C}$ higher than conventional; moreover, total phenols content and number average molecular weight of tannins in the effluent decreased with microwave inducing [10]. During the process of collagen crosslinked with tannic acid, the Ts, denaturation temperature and enthalpy of product reacted with microwave-assisting increased by $3.5^{\circ} \mathrm{C}, 3.9^{\circ} \mathrm{C}$ and $73.0 \mathrm{~J} / \mathrm{g}$ [11]. The Ts and denaturation temperature of zirconium tanned hider powders under microwave were $1.3-2.4{ }^{\circ} \mathrm{C}$ and $2.2-$ $3.4^{\circ} \mathrm{C}$ higher compared with the samples tanned under water bath heating [12]. When microwave was used in chrome tanning process, Ts and tear of the leather could increase by $2.5^{\circ} \mathrm{C}$ and $7.5 \mathrm{~N} / \mathrm{mm}$ respectively at most [13], and hexavalent chromium content of the product was below detection limit even after UV accelerated aging [14]. Furthermore, microwave had special effect which could make leather Ts higher than $100^{\circ} \mathrm{C}$ when terminal $\mathrm{pH}$ of chrome tanning was only 3.3 [15].

As well known, various kinds of chromium complex results in huge difference on tanning effect, for example, the shrinkage temperature of chromium sulphate tanned leather is usually higher than $100^{\circ} \mathrm{C}$, while the chromium chloride, chromium nitrate and chromium perchlorate tanned leathers only increase the shrinkage temperature to $95^{\circ} \mathrm{C}, 75^{\circ} \mathrm{C}$ and $70^{\circ} \mathrm{C}$ respectively [16]. The different chromium complex composition should be responsible for the diversity [17-20]. Ion exchange chromatography (IEC) and gel filtration chromatography (GFC) were widely used to study the composition of chromium tanning liquor [21, 22] and they also had been used to clarify chromium complex composition in leather making to provide hint for cleaner process [23, 24]. Hitherto, it had been proven that microwave could promote the hydrolysis and olation chromium tanning liquor further due to existence of non-thermal effect [25, 26]. However, how does microwave affect the chromium complex composition in tanning liquor? It is still in puzzle. In the study, the most widely used chromium tanning liquor, chromium sulphate, would be subjected microwave and water bath heating at first, and then IEC and GFC were applied to separate the complexes to explicate the differences on composition between two heating methods. In addition, FT-IR would be used characterize the structure of each chromium complexes. Finally, the chromium tanning liquor heated by microwave and water bath were used in hide powder tanning, and then chrome exhaustion as well as thermal stability of the products were determined. This work would explain the detail effects of microwave on hydrolysis and olation chromium tanning liquor and provide theoretical basis for applying microwave in tanning agent modification and chrome tanning process.

\section{Experimental}

\subsection{Reagents and materials}

Chromium sulphate hexahydrate was purchased from Shanghai Aladdin Reagents Company. SP Sephadex C25 cation exchange resins and SP Sephadex G-25 glucan gel resins were bought from GE Healthcare. Hide powder was from Tanning Chemical Lab of Chinese Academy of Forestry Sciences in Nanjing. All the other chemicals used in the study were research grade reagents commercially purchased from Chengdu Kelong Chemical Ltd., China.

\subsection{Instruments}

MCR-3C microwave reactor (Xi'an Yuhui instrument Ltd.) and DF-101S water bath heater (Wuhan Ke'er instrument Company) were used as heating resources respectively. UV1900 UV-Vis spectrometer (Shanghai Jinghua instrument Co.) and Nicolet 10 FT-IR (American Thermo Scientific Corporation) were used for characterizing the structure of chromium complexes. Optima 8000DV Inductively Coupled Plasma Atomic Emission Spectroscopy (ICP-AES, PerkinElmer, America), DSC 200 PC differential scanning calorimeter (NETZSCH, Germany) and NETZSCH TG 209 F1 thermal gravimetric analyzer (NETZSCH, Germany) were used to measure tanning effects of hide powder.

\subsection{Sample preparation}

\subsubsection{Samples for IEC and GFC determination}

$0.2 \mathrm{~mol} / \mathrm{L}$ chromium tanning liquor ( $0 \%$ basicity) was prepared by dissolving $10.00 \pm 0.01 \mathrm{~g}$ chromium sulphate in $100 \mathrm{~mL}$ distilled water and then stirred for $30 \mathrm{~min}$

$10.00 \pm 0.01 \mathrm{~g}$ chromium sulphate hexahydrate was dissolved in $80 \mathrm{~mL}$ distilled water at first, then $0.560 \pm$ $0.005 \mathrm{~g}$ sodium bicarbonate was dissolved in $20 \mathrm{~mL}$ distilled water, finally, the sodium bicarbonate solution was added into chromium sulphate solution within $30 \mathrm{~min}$ under stirring. After another $30 \mathrm{~min}$ mixing, the 0.2 $\mathrm{Mol} / \mathrm{L}$ chromium tanning liquor with $33 \%$ basicity was produced and the basicity measurement result was $31.76 \%$

Fifty milliliter of both chromium tanning liquors were injected in $100 \mathrm{~mL}$ beaker, and then the systems were heated with microwave reactor, regrading as MW, and water bath heater, regrading as $\mathrm{WB}$, at $50^{\circ} \mathrm{C}$ for $60 \mathrm{~min}$ respectively. The solutions were cooled down and left with 60 min after warming. The chromium tanning liquors without any heating were control. 


\subsubsection{Tanning trial}

The $60 \mathrm{~g} / \mathrm{L}$ sodium chloride solution was used as solvent for tanning and preparing tanning liquor. $13.16 \pm 0.01 \mathrm{~g}$ chromium sulphate hexahydrate was dissolved in 300 $\mathrm{mL}$ sodium chloride solution at first, then $0.7370 \pm$ 0.005 g sodium bicarbonate was dissolved in $100 \mathrm{~mL}$ sodium chloride solution, finally, the sodium bicarbonate solution was added into chromium sulphate solution within 30 min under stirring. After another $30 \mathrm{~min}$ mixing, chrome tanning liquor with $33 \%$ basicity was prepared. One hundred milliliter of the chrome tanning liquors were warmed by microwave irradiation and water bath at $50{ }^{\circ} \mathrm{C}$ for $60 \mathrm{~min}$ respectively, the solutions were used for subsequent tanning trials after cooling down to room temperature.

$5.00 \pm 0.01 \mathrm{~g}$ hide powder were put into a $250 \mathrm{~mL}$ flask and soaked with $50 \mathrm{~mL}$ sodium chloride solution for 30 min. Fifty milliliter chrome tanning liquor warmed by microwave and water bath heating was added respectively, the flasks were shaken at $40^{\circ} \mathrm{C}$ for $30 \mathrm{~min}$ and then $6 \mathrm{~mL} 0.1 \mathrm{~mol} / \mathrm{L}$ sodium hydroxide were used to adjust the tanning $\mathrm{pH}$ to about 4.0 at last, the flasks after basification were shaken again under same condition for another $30 \mathrm{~min}$ to finish tanning. The mixture was filtrated by 100 meshes nylon filter cloth to separate the tanning effluent and chrome tanned hide powder. The chrome tanned hide powder was lyophilized for subsequent analyses. The tanning by using microwave irradiation heated chrome tanning liquor was regard as $\mathrm{MW}$ and by water bath heating was short for WB.

\subsection{Determination methods}

\subsubsection{Ion exchange chromatography determination}

Five milliliter of each sample was filtered by microporous membranes (pore size $450 \mathrm{~nm}$ ), and then added into pretreated SP Sephadex C-25 cation exchange chromatographic columns (inner diameter 2.0 $\mathrm{cm}$, packed $20.0 \mathrm{~cm}$ ). Elution conditions were selected as follows: flow velocity of eluent of $2.5 \mathrm{~mL} / \mathrm{min}$, followed by using $\mathrm{H}_{2} \mathrm{O}, 0.5 \mathrm{~mol} / \mathrm{L} \mathrm{NaClO}_{4}, 1.0 \mathrm{~mol} / \mathrm{L}$ $\mathrm{NaClO}_{4}, 2.0 \mathrm{~mol} / \mathrm{L} \mathrm{NaClO}_{4}, 2.0 \mathrm{~mol} / \mathrm{L} \mathrm{HCl}$ and 2.0 $\mathrm{mol} / \mathrm{L} \mathrm{HCl}$ to elute. UV1900 UV-Vis spectrophotometer was used to detect the absorbance at $420 \mathrm{~nm}$ for each $7.5 \mathrm{~mL}$ eluent $[23,24,27]$.

\subsubsection{Gel filtration chromatography determination}

Five milliliter of each sample was filtered by microporous membranes (pore size $450 \mathrm{~nm}$ ), and then put into pretreated SP Sephadex G-25 gel filtration chromatographic columns (inner diameter $2.0 \mathrm{~cm}$, packed $80.0 \mathrm{~cm}$ ). Elution conditions were selected as follows: flow velocity of eluent, $2.5 \mathrm{~mL} / \mathrm{min} ; \mathrm{H}_{2} \mathrm{O}$ was used to elute. UV1900 UV-Vis spectrophotometer was used to detect the absorbance at $420 \mathrm{~nm}$ for each $7.5 \mathrm{~mL}$ eluent $[23,24,27]$.

\subsubsection{Chromium structure determination}

After IEC separation, each composition was lyophilized. The lyophilized chromium composition from IEC separation was ground with $\mathrm{KBr}$ and made into thin disk, then a Nicolet 10 FT-IR was used to scan in wavenumber range of $500-4000 \mathrm{~cm}^{-1}$ for 32 times, and the data was recorded.

\subsubsection{Hide powder chrome content measurement}

$0.150 \pm 0.001 \mathrm{~g}$ lyophilized chrome tanned hide powder was digested in a flask with $10 \mathrm{~mL}$ nitric acid and $5 \mathrm{~mL}$ hydrogen peroxide under boiling for $30 \mathrm{~min}$ until there was no visible particle. After cooling down, the digested solution was dissolved in $100 \mathrm{~mL}$ volumetric flask. The total chromium content in digestion solution was determined by ICP-AES following the manufacturer's direction and then the content of $\mathrm{Cr}_{2} \mathrm{O}_{3}$ in hide powder was calculated.

\subsubsection{Hide powder DSC measurement}

The lyophilized chrome tanned hide powder was put into aluminum crucibles and heated by differential scanning calorimeter with $10^{\circ} \mathrm{C} / \mathrm{min}$ heating rate in $100 \mathrm{~mL} /$ min nitrogen atmosphere from 50 to $250^{\circ} \mathrm{C}$.

\subsubsection{Hide powder TG measurement}

The lyophilized chrome tanned hide powder was put into ceramic crucibles and heated by thermal gravimetric analyzer with $10^{\circ} \mathrm{C} / \mathrm{min}$ heating rate in $100 \mathrm{~mL} / \mathrm{min} \mathrm{ni-}$ trogen atmosphere from 50 to $800^{\circ} \mathrm{C}$.

\section{Results and discussion}

\subsection{The influence of microwave on chromium charge} composition in tanning liquor

The IEC results of $0 \%$ basicity chromium sulphate tanning liquors warmed under microwave (MW), water bath (WB) and without heating are shown in Fig. 1. According to prior studies, the chromatographic peak I to peak VI represent anionic-zerovalent, monovalent, bivalent, trivalent, tetravalent and pentavalent chromium complexes respectively [23, 24, 27]. The contents of each composition in WB, MW and control can be calculated based on the area of ion-exchange chromatographic peaks and the results are listed in Table 1.

Generally, hydrolysis results in the ligand change of chromium complex and $\mathrm{pH}$ reducing of tanning liquor; olation leads to generate high positive charge and large molecular size chromium complex. Notably, the control sample consists of anionic-zerovalent complex mainly, the content is $69.55 \%$, while the high positive compositions, tetravalent and pentavalent chromium complex, 
$0 \%$ basicity control

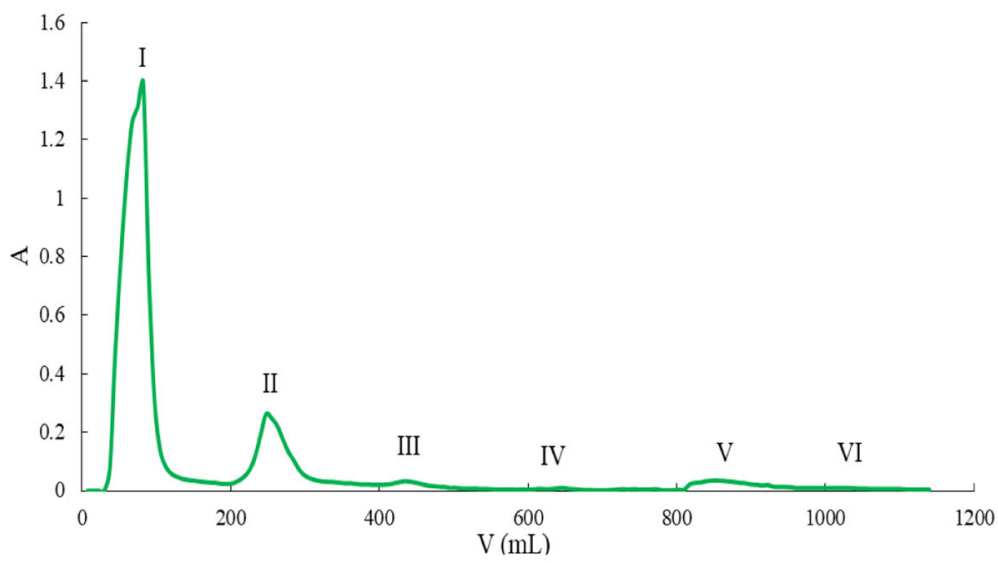

$0 \%$ basicity WB

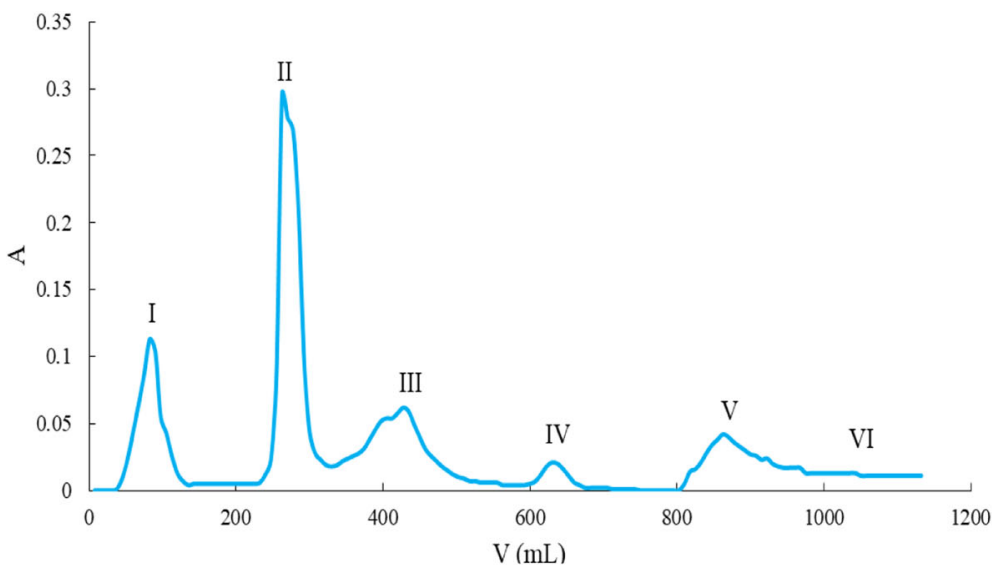

$0 \%$ basicity MW

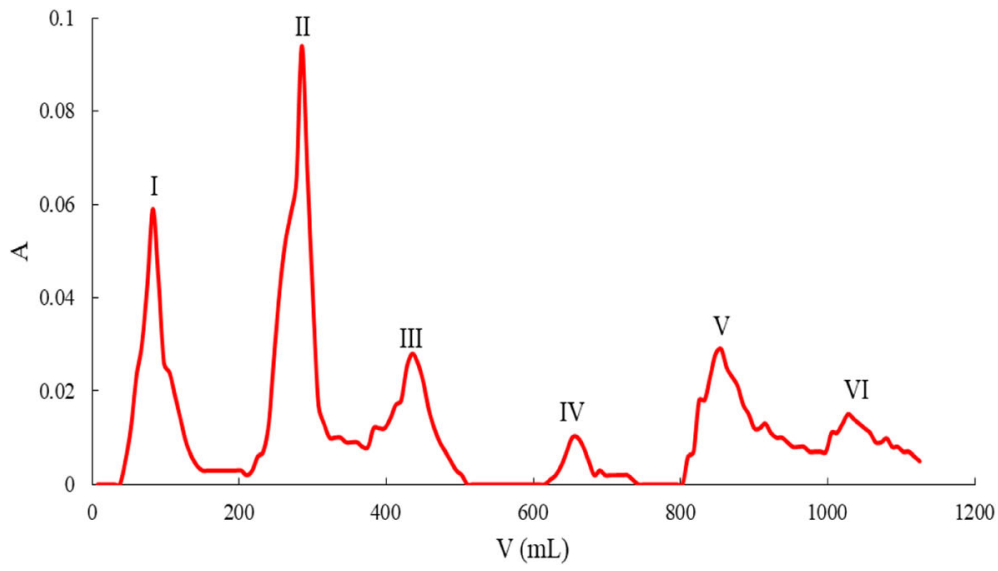

Fig. 1 The IEC results of 0\% basicity chromium sulphate tanning liquors warmed under different methods

are relatively less. After warming, the anionic-zerovalent complex decreases to $15.59 \%$ for WB and $18.01 \%$ for MW, but other positive charge complexes increase obviously, indicating warming promotes chromium tanning liquor hydrolysis and olation to generate more positive charge complexes. Furthermore, there are more tetravalent and pentavalent chromium complexes in MW which are $3.76 \%$ and $5.94 \%$ higher in comparison with WB. That is to say, microwave has more powerful and significant effect on promoting the hydrolysis and olation process because microwave contains the effect beyond temperature named non-thermal effect. 
Table 1 The content of each component in 0\% basicity chromium sulphate tanning liquor warmed under different methods

\begin{tabular}{llll}
\hline Composition & Control (\%) & WB (\%) & MW (\%) \\
\hline I & 69.55 & 15.59 & 18.01 \\
II & 18.50 & 38.10 & 31.18 \\
III & 4.59 & 20.90 & 17.10 \\
IV & 1.17 & 4.61 & 3.21 \\
V & 3.87 & 9.88 & 13.64 \\
VI & 2.32 & 10.92 & 16.86 \\
Total & 100.00 & 100.00 & 100.00 \\
\hline
\end{tabular}

Figure 2 and Table 2 are the IEC results of 33\% basicity chromium sulphate tanning liquors warmed under microwave (MW), water bath (WB) and without heating together with the contents of each composition in different samples. As expected, less anionic-zerovalent complex but more positive charge complexes is found in $33 \%$ basicity chromium sulphate tanning liquor after warming. The anionic-zerovalent chromium complexes in WB and MW decrease by $20.69 \%$ and $20.80 \%$ compared with control. In addition, pentavalent chromium complexes in MW are $9.65 \%$ and $8.11 \%$ higher than control and WB.

Since previous has been demonstrated microwave had non-thermal effect when it was used for heating chromium tanning liquor, the detail reason for the changes was not explicated. No matter chromium (III) or ligands, water, hydroxyl ion or sulphateanion, are polar particles, they are affected by microwave and generated unforced oscillation to produce more complicated movement styles and greater collision possibility during hydrolysis and olation, which benefit for higher reaction rate and yield. Thus, the hydrolysis and olation of chromium sulphate tanning liquors are drastic under microwave and result in generating more positive charge complexes. As the temperature during microwave and water bath warming process is same, the additional positive charge complexes might be attributed to non-thermal effect of microwave.

\subsection{The influence of microwave on chromium molecular size in tanning liquors}

GFC is widely used to analyze molecular size distribution of mixture. During the process, retention time of large molecular size composition is short; on the contrary, it is long for small molecular size part. The GFC results of $0 \%$ and $33 \%$ basicity chromium sulphate tanning liquors with different warming treatments are shown in Fig. 3. In the both basicity liquors, retention time from short to long is always MW, WB and control, and the retention time of $33 \%$ basicity samples are shorter than corresponding of $0 \%$ basicity.
The hydrolysis and olation of chromium complex could be illustrated as following schematic:

Hydrolysis: $\left[\mathrm{Cr}\left(\mathrm{H}_{2} \mathrm{O}\right)_{6}\right]^{3+} \rightarrow\left[\left(\left[\mathrm{Cr}(\mathrm{OH})\left(\mathrm{H}_{2} \mathrm{O}\right)_{5}\right]^{2+}+\mathrm{H}^{+}\right.\right.$

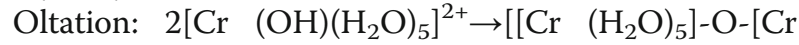
$\left.\left.\left(\mathrm{H}_{2} \mathrm{O}\right)_{5}\right]\right]^{3+}+\mathrm{H}^{+}$.

Just as the IEC results, there are more high positive charge composition after warming, as consequence, more multinuclear complexes are generated and result in enlarging average molecular size of chromium complex in tanning liquors.

Compared with $0 \%$ basicity chromium sulphate tanning liquor, which mainly contains $\left[\mathrm{Cr}\left(\mathrm{H}_{2} \mathrm{O}\right)_{6}\right]^{3+}$ at beginning, the dominant complexes in $33 \%$ basicity chromium sulphate tanning liquor is $\left[\mathrm{Cr}(\mathrm{OH})\left(\mathrm{H}_{2} \mathrm{O}\right)_{5}\right]$ ${ }^{2+}$. There is only one kind of ligand in $\left[\mathrm{Cr}\left(\mathrm{H}_{2} \mathrm{O}\right)_{6}\right]^{3+}$ while two ligands exist in $\left[\mathrm{Cr}(\mathrm{OH})\left(\mathrm{H}_{2} \mathrm{O}\right)_{5}\right]^{2+}$. The different ligand changes the space structure and electronic cloud distribution of complex, causing polarity transformation. Obviously, complex in 33\% basicity chromium sulphate tanning liquor has larger polarity due to hydroxyl ion inducing. With the increasing of basicity, retention time in $33 \%$ basicity tanning liquor for $\mathrm{MW}$ is $12 \mathrm{~min}$ shorter than WB (from $111 \mathrm{~min}$ to $99 \mathrm{~min}$ ) and only $6 \mathrm{~min}$ shorter (from $135 \mathrm{~min}$ to $129 \mathrm{~min}$ ) in $0 \%$ basicity specimen. That is to say, microwave has more significant effect on hydrolysis and olation of chromium sulphate tanning liquor when it has higher polarity because microwave has more significant effect on polar system.

\subsection{The influence of microwave on chromium complex structure}

FT-IR absorption peaks and coordination patterns between chromium and $\mathrm{SO}_{4}{ }^{2-}$ of each composition separated by IEC in $0 \%$ and $33 \%$ basicity chromium sulphate tanning liquors with different warming treatments are shown in Tables 3 and 4. In FT-IR results, the combination pattern between $\mathrm{Cr}$ (III) and $\mathrm{SO}_{4}{ }^{2-}$ is double-point coordination if there are four absorption peaks in the range of $900-1300 \mathrm{~cm}^{-1}$; meanwhile, the combination pattern between $\mathrm{Cr}$ (III) and $\mathrm{SO}_{4}{ }^{2-}$ is single-point coordination if there are three absorption peaks in the range of $900-1300 \mathrm{~cm}^{-1}$; if there are two absorption peaks, $\mathrm{SO}_{4}{ }^{2-}$ is free [28].. The FT-IR images (wavelength from 800 to $2000 \mathrm{~cm}^{-1}$ ) of each component separated from chromium sulphate tanning liquor with two kinds of basicity are listed in Fig. S1 to Fig. S6, and the peaks of $\mathrm{SO}_{4}{ }^{2-}$ in chromium complex are showed in Tables 3 and 4.

For $0 \%$ basicity chromium sulphate tanning liquors, there are three, two, two and two absorption peaks in composition I composition II, composition III and composition IV for control. The absorption peaks for corresponding compositions in WB and MW are totally 
$33 \%$ basicity control

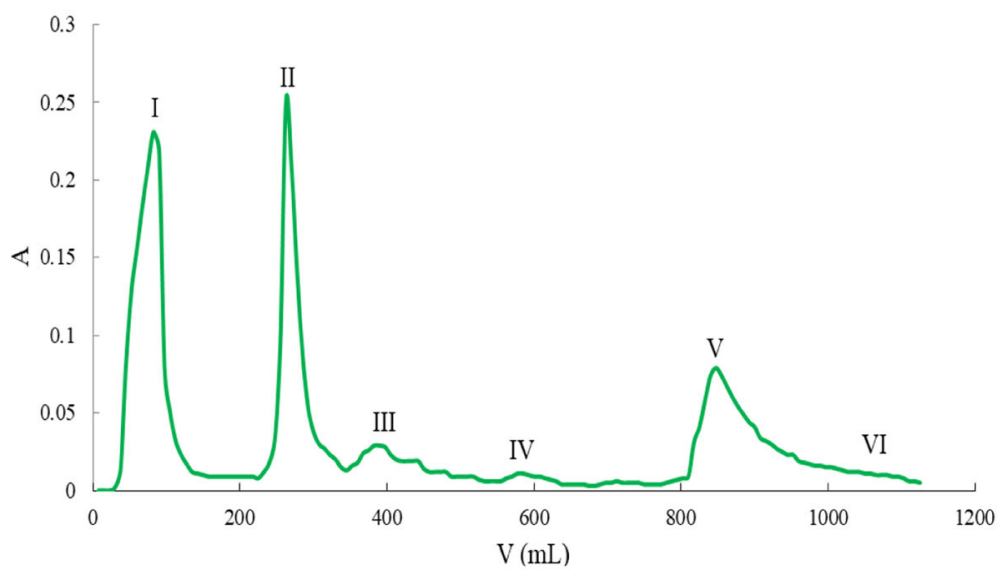

$33 \%$ basicity WB

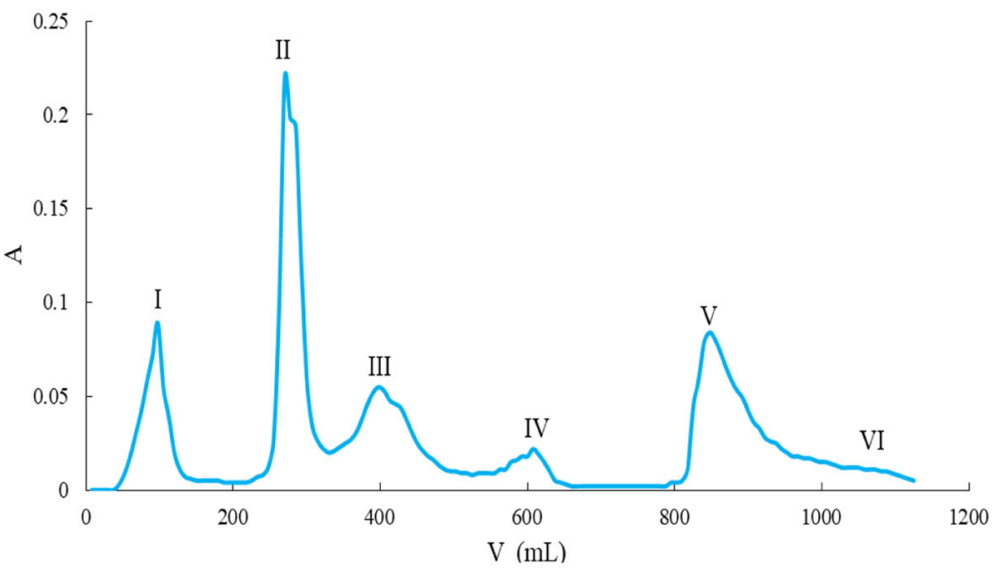

$33 \%$ basicity MW

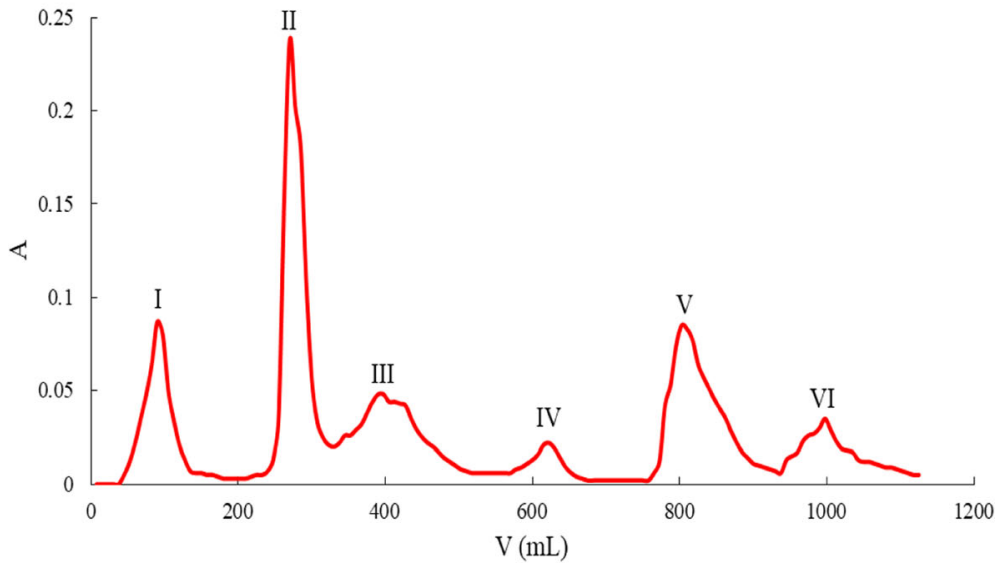

Fig. 2 The IEC results of 33\% basicity chromium sulphate tanning liquors warmed under different methods

same, but the one more peak are observed in composition I and composition III from WB and MW compared with control.

For 33\% basicity chromium sulphate tanning liquor, the number of absorption peaks of each component in WB and MW samples is still same; two more absorption peaks in composition III are observed in WB and MW compared with control.

These results indicate heating can alter the combination pattern of chromium complex as consequence of converting single-point coordination into double-point coordination. In this way, much higher positive charge 
Table 2 The content of each component in 33\% basicity chromium sulphate tanning liquor warmed under different methods

\begin{tabular}{llll}
\hline Composition & Control (\%) & WB(\%) & MW(\%) \\
\hline I & 33.12 & 12.43 & 12.32 \\
II & 26.07 & 29.89 & 30.33 \\
III & 9.57 & 19.29 & 18.02 \\
IV & 3.62 & 6.01 & 5.94 \\
V & 25.60 & 28.83 & 21.73 \\
VI & 2.02 & 3.56 & 11.67 \\
Total & 100.00 & 100.00 & 100.00 \\
\hline
\end{tabular}

complexes and the complexes with larger molecular size are generated. Nevertheless, although microwave promotes the hydrolysis and olation further and brings about more positive charge and large molecular size complexes in comparison with water bath, the coordination pattern in $\mathrm{MW}$ is completely same with $\mathrm{WB}$, indicating microwave only accelerates the reaction and leads to high yield rather than changing the mechanism of hydrolysis and olation.

The frequency of microwave for civil application is $2450 \mathrm{MHz}$ in China. Usually, the energy of light quantum of microwave is only $10^{-5} \mathrm{eV}$. Since the ionic and covalent bond energy are about 5 to $7 \mathrm{eV}$, even the hydrogen bond energy is $0.04-0.44 \mathrm{eV}$, microwave could
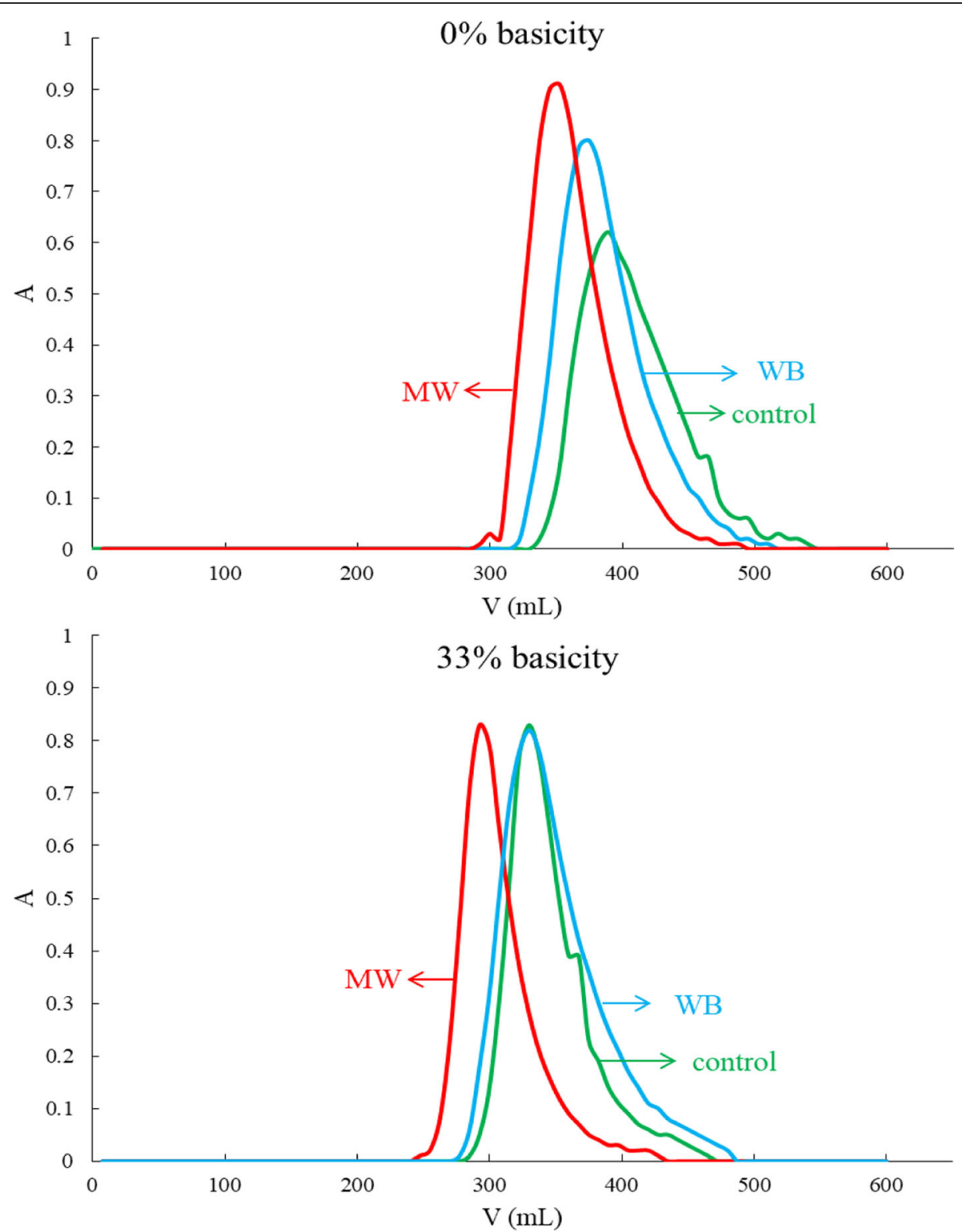

Fig. 3 The GFC results of chromium sulphate tanning liquors warmed under different methods 
Table 3 FT-IR absorption peaks of $\mathrm{SO}_{4}{ }^{2-}$ in chromium complex from each component in $0 \%$ basicity chromium sulphate tanning liquor

\begin{tabular}{llll}
\hline Composition & Control $\left(\mathrm{cm}^{-1}\right)$ & WB $\left(\mathrm{cm}^{-1}\right)$ & MW $\left(\mathrm{cm}^{-1}\right)$ \\
\hline I & 1095.23 & 1288.00 & 1289.42 \\
& 988.29 & 1206.79 & 1210.51 \\
& 941.27 & 1065.74 & 1067.67 \\
II & & 980.87 & 981.54 \\
& 1110.72 & 1028.28 & 1116.50 \\
III & 940.51 & 940.05 & 940.23 \\
& 1087.29 & 1106.16 & 1118.32 \\
& 940.62 & 1083.89 & 1081.91 \\
IV & & 940.72 & 940.67 \\
& 1114.61 & 1099.29 & 1106.98 \\
V & 940.82 & 940.83 & 940.69 \\
& - & 1157.35 & 1141.84 \\
& & 1140.73 & 1110.72 \\
& & 1065.05 & 1087.21 \\
& & 940.69 & 940.71 \\
\hline
\end{tabular}

not break any chemical bond from views of energy aspect [29]. Not surprisingly, the combination patterns between chromium and ligands remain under microwave irradiation. The polar ions which could absorb microwave and result in more complicated movement beyond thermal will have larger collision possibility during

Table 4 FT-IR absorption peaks of $\mathrm{SO}_{4}{ }^{2-}$ in chromium complex from each component in $33 \%$ basicity chromium sulphate tanning liquor

\begin{tabular}{llll}
\hline Composition & Control $\left(\mathrm{cm}^{-1}\right)$ & WB $\left(\mathrm{cm}^{-1}\right)$ & MW $\left(\mathrm{cm}^{-1}\right)$ \\
\hline 1189.29 & 1284.33 & 1284.57 \\
& 1068.27 & 1178.76 & 1178.86 \\
& 1045.80 & 1069.34 & 1069.59 \\
& 975.35 & 940.78 & 1010.94 \\
II & 1049.46 & 1095.49 & 1083.95 \\
& 940.15 & 940.18 & 940.37 \\
III & 1114.62 & 1144.60 & 1144.92 \\
& 940.44 & 1111.03 & 1111.18 \\
& & 1086.89 & 1084.19 \\
& & 940.64 & 940.63 \\
& & 1114.66 & 1084.22 \\
V & & 940.42 & 940.64 \\
& 1142.08 & 1145.47 & 1144.81 \\
& 1111.14 & 1113.81 & 1112.94 \\
& 1087.24 & 1088.73 & 1087.89 \\
& 940.67 & 940.80 & 940.78 \\
\hline
\end{tabular}

hydrolysis and olation to make the reaction more effective. It could be explicate the results that microwave increases the ratio of high positive charge and large molecular size complexes without changing combination between chromium (III) and ligands.

\subsection{The influence of microwave on tanning ability of chromium tanning liquor}

As microwave could promote the hydrolysis and olation of chromium tanning liquor further to generate more high-positive charge and large molecular size complexes, it would benefit for improving tanning ability of chromium tanning liquor. Hide powder was tanned by 33\% basicity chromium tanning liquor treated by microwave and water bath in advance, and then the chrome content and thermal behaviors of the products were measured.

Generally, the more high-positive charge and large molecular size complexes exist, the better tanning ability of the chromium tanning liquor is. The 33\% basicity chromium tanning liquor after water bath and microwave heating was used in hide powder tanning, and denaturation and thermal decomposition process of the tanned hide powder are shown in Figs. 4 and 5. The critical data like denaturation temperature $\left(\mathrm{T}_{\mathrm{d}}\right)$, enthalpy during denaturation $(\Delta \mathrm{H})$, maximum decomposition temperature $\left(\mathrm{T}_{\max }\right)$, carbon residue and chrome content are listed in Table 5 .

It is clear that $\mathrm{Cr}_{2} \mathrm{O}_{3}$ content of MW sample is higher than WB because there are more high positive charge and large molecular size complexes in tanning liquor after microwave heating which have better affinity to collagen and result in higher chrome exhaustion during tanning. Since chrome content is higher in MW sample and there may be more high-positive charge and large molecular size complexes combined with collagen during tanning, it might establish more cross-linking between collagen and chromium complexes, thus the product has better thermal stability presenting as higher $\mathrm{T}_{\mathrm{d}}, \Delta \mathrm{H}$ and $\mathrm{T}_{\max }$. Moreover, as the chromium complex is nonvolatile substance, the higher chrome content in MW is an important reason for higher carbon residue compared with WB. These results suggest that chromium tanning liquor undertook microwave irradiation has better tanning ability which could make leather have better thermal stability and thermal decomposition resistance as well as improve chrome exhaustion during tanning.

\section{Conclusion}

The promotion effects of microwave on chromium tanning liquor come from both thermal effect and nonthermal effect. There are more high positive charge and large molecular size complexes in chromium tanning liquor after microwave heating due to the existence of 


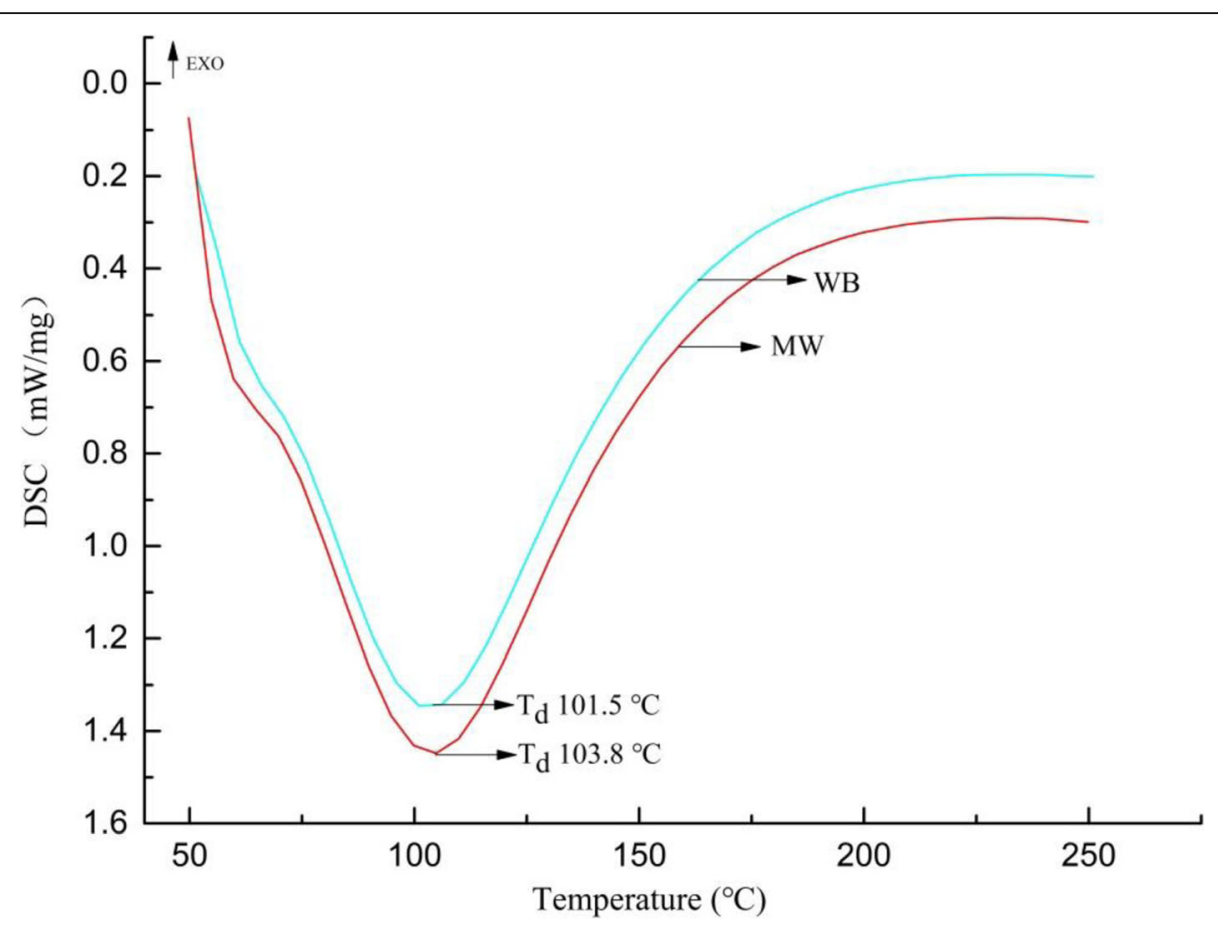

Fig. 4 The denaturation process of hide powder tanned by chrome tanning liquor treated by different method

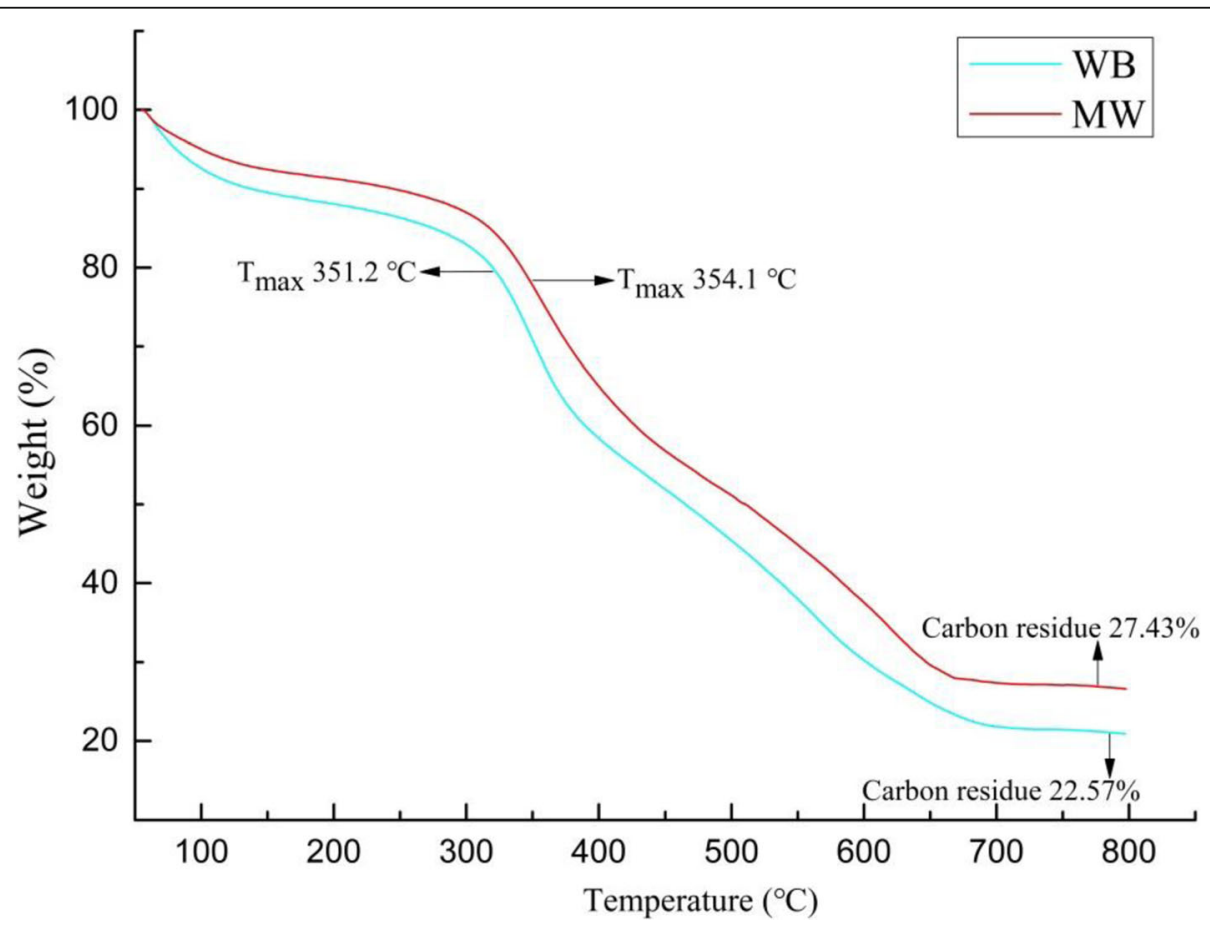

Fig. 5 The thermal decomposition process of hide powder tanned by chrome tanning liquor treated by different method 
Table 5 The thermal behaviors and chrome content of hide powder tanned by chrome tanning liquor treated by different method

\begin{tabular}{llllll}
\hline Sample & $\mathrm{T}_{\mathrm{d}}\left({ }^{\circ} \mathrm{C}\right)$ & $\Delta \mathrm{H}(\mathrm{J} / \mathrm{g})$ & $\mathrm{T}_{\max }\left({ }^{\circ} \mathrm{C}\right)$ & Carbon residue (\%) & $\mathrm{Cr}_{2} \mathrm{O}_{3}$ content $(\mathrm{mg} / \mathrm{kg})$ \\
\hline WB & 101.5 & 373.2 & 351.2 & 22.57 & 46.78 \\
MW & 103.8 & 392.4 & 354.1 & 27.43 & 53.81
\end{tabular}

non-thermal effect. Microwave has stronger influence on $33 \%$ basicity chromium tanning liquor hydrolysis and olation, in other word, high polarity system are affected by microwave drastically and effectively. Although microwave has additional effect on chromium tanning liquor hydrolysis and olation, the combination patterns between chromium and ligand remain as normal. There is better tanning ability to generate excellent thermal behaviors leather and improve chrome exhaustion during tanning when chromium tanning liquor is treated by microwave irradiation. To summarize, microwave might be a new method for modifying chrome tanning agent in future and would be used in chrome tanning process in one step.

\section{Supplementary information}

Supplementary information accompanies this paper at https://doi.org/10. 1186/s42825-020-00024-1.

\begin{abstract}
Additional file 1: Fig. S1. FT-IR images of each component in $0 \%$ basicity chromium sulphate tanning liquor without heating. Fig. S2. FT-IR images of each component in $0 \%$ basicity chromium sulphate tanning liquor with water bath heating. Fig. S3. FT-IR images of each component in $0 \%$ basicity chromium sulphate tanning liquor with microwave irradiation. Fig. S4. FT-IR images of each component in 33\% basicity chromium sulphate tanning liquor without heating. Fig. S5. FT-IR images of each component in 33\% basicity chromium sulphate tanning liquor with water bath heating. Fig. S6. FT-IR images of each component in 33\% basicity chromium sulphate tanning liquor with microwave irradiation.
\end{abstract}

\section{Abbreviations}

MW: Microwave; IEC: Ion exchange chromatography; GFC: Gel filtration chromatography; WB: Water bath heating; Ts: Shrinkage temperature; UVVis: Ultraviolet-visible spectroscopy; FT-IR: Fourier transform infrared spectroscopy; DSC: Differential scanning calorimeter; TG: Thermogravimetric analysis; $T_{d}$ : Denaturation temperature; $\Delta \mathrm{H}$ : Enthalpy during denaturation; $T_{\text {max }}$ : Maximum decomposition temperature

\section{Acknowledgements}

The authors wish to thank the financial support of National Natural Science Foundation of China (No. 21576171).

\section{Authors' contributions}

Zhang Jinwei mainly focused on finishing experiments and analyzing data, he also wrote draft of the manuscript. Chen Wuyong was responsible for designing the experiments and revising the manuscript. Carmen Gaidau helped anylyse data and revise the manuscript. The author(s) read and approved the final manuscript.

\section{Authors' information}

Dr. Zhang Jinwei got his Ph. D. degree at 2018 in major of leather chemistry and engineering. He is an engineer in Lab for leather making technology (College of Biomass Science and Engineering, Sichuan University) and interested in leather making chemistry and technology, clean technology for leather manufacturing and functional leather products.

Prof. Chen Wuyong is a famous scientist and educationist in major of leather chemistry and engineering. His research area contains leather making chemistry, tanning chemistry, plant polyphenol chemistry and functional leather products etc.

Dr. Carmen Gaidau is head of Leather Research Department in Leather and Footwear Research Institute Division Romania. She mainly focus on developing nano-material for functional leather making, collagen midification and application as well as clean technology for leather manufacturing.

\section{Funding}

National Natural Science Foundation of China (No. 21576171).

\section{Availability of data and materials}

Not applicable.

\section{Competing interests}

No conflict of interest exits in the submission of this manuscript, and manuscript is approved by all authors for publication.

\section{Author details}

${ }^{1}$ Key Laboratory of Leather Chemistry and Engineering of Ministry of Education, Sichuan University, Chengdu 610065, China. ${ }^{2}$ College of Biomass Science and Engineering, Sichuan University, Chengdu 610065, China. ${ }^{3}$ R\&D National institute for Textile and Leather-Division Leather and Footwear Research Institute, 031215 Bucharest, Romania.

Received: 15 November 2019 Accepted: 1 April 2020

Published online: 16 April 2020

\section{References}

1. Kitchen HJ, Vallance SK, Kennedy JL, Tapia-Ruiz N, Carassiti L, Harrison A, Whittaker AG, Drysdale TD, Kingman SW, Gregory DH. Modern microwave methods in solid-state inorganic materials chemistry: from fundamentals to manufacturing. Chem Rev. 2014;114:1170-206.

2. Baig RBN, Varma RS. Alternative energy input: mechanochemical, microwave and ultrasound-assisted organic synthesis. Chem Soc Rev. 2012;41:1559-84.

3. Adam D. Microwave chemistry: out of the kitchen. Nature. 2003:421:571-2.

4. Diaz-Ortiz A, Prieto P, de la Hoz A. A critical overview on the effect of microwave irradiation in organic synthesis. Chem Rec. 2019;19:85-97.

5. Zhang JW, Wu JC, Chen WY. Special review paper: applications of microwave in leather field: further research for leather chemists and technologists. J Am Leather Chem Assoc. 2017;112:311-8.

6. Gong Y, Cheng K, Zhang T, Chen WY. Automated clear leather dyeing assisted by wringing, ultrasound and microwave. J Am Leather Chem Assoc. 2011;106:127-32.

7. Gong Y, Zhang T, Chen WY. Behavior of fatliquored leathers in a microwave field. J Am Leather Chem Assoc. 2012;107:60-7.

8. Wu JC, Sun T, Zhang JW, Chen WY. Interaction of enzymes and hide/leather based on microwave. J Soc Leather Technol Chem. 2018;102:204-9.

9. Zhang JW, Zhang CL, Wu JC, Chen WY. The influence of microwave nonthermal effect on leather properties in drying. J Am Leather Chem Assoc. 2017;112:135-9.

10. Wu JC, Fan ZW, Zhang JW, Wang Y, Chen WY. Impact of microwave irradiation on vegetable tanning. J Soc Leather Technol Chem. 2018;102:7-11.

11. Wu JC, Liao W, Zhang JW, Chen WY. Thermal behavior of collagen crosslinked with tannic acid under microwave heating. J Therm Anal Calorim. 2019;135:2329-35.

12. Fang $Y T$, Zhang JW, Ning GQ, Chen WY. Effects of microwave irradiation on hydrolysis of zirconium sulphateand thermal stability of zirconium tanned powder. Leather Sci Eng. 2017;27:12-6.

13. Wang H, Chen WY, Gong Y, Sun HB. Based on the studies of chrome tanning chemistry with microwave. Leather Sci Eng. 2011;21:5-9.

14. Chen J, Zhang JW, Zhou N, Chen WY. Influence of microwave irradiation on the stability of chromium (III) complexes. Leather Sci Eng. 2017;27:5-9. 
15. Zhang JW, Chen WY, Gaidau C. Microwave irradiation: an innovative routine to promote goat skin chrome tanning process. J Am Leather Chem Assoc. 2019;114:287-92

16. Li GY, Chen J, Zhang MR. Relation between the compositions of chrome tanning liquors and their tanning properties. Leather Chem. 1999;16:1-7,18.

17. Li GY, Chen J, Zhang MR. Study on the composition of complexes in chrome sulphate tanning liquors. China Leather. 1992;21:8-19.

18. Li GY, Chen J, Zhang MR. Study on the composition of complexes in chrome chloride tanning liquors. China Leather. 1993;22:18-23 28.

19. Li GY, Chen J, Zhang MR. Study on the composition of complexes in chrome nitrate tanning liquors. China Leather. 1993;22:18-24.

20. Li GY, Chen J, Zhang MR. Study on the composition of complexes in chrome perchlorate tanning liquors. China Leather. 1993;22:17-20 42.

21. Rao JR, Nair BU, Ramasami T. Isolation and characterization of a low affinity chromium (III) complex in chrome tanning solutions. J Soc Leather Technol Chem. 1997:81:234-8.

22. Molik A, Siepak J, Dojlido R, Swietlik JR. Identification of chromium species in tanning solutions. Pol J Environ Stud. 2014;13:311-4.

23. Wu JC, Gao YP, Zhang JW, Wang Y, Chen WY. Chrome complexes in rewetting and neutralizing effluents and hints for recycling post-tanning wet-process effluent. Pol J Environ Stud. 2018;27:1315-21.

24. Zhang JW, Gao YP, Chen WY. Characteristics of chrome complexes in neutralizing effluent. Leather Footwear J. 2017;17:45-50.

25. Cao N, Zhang JW, Wang SJ, Chen WY. Behaviors of chromium nitrate hydrolysis and olation under microwave irradiation. Leather Sci Eng. 2016; 26:5-9.

26. Zhang JW, Cao N, Zhou N, Chen WY. Hydrolysis and olation of chromium sulphate under microwave irradiation. J Soc Leather Technol Chem. 2017; 101:1-5.

27. Gao YP, Hu J, Zhang JW, Sun HB, Luo GS, Chen WY. Research on composition of chrome complexes in rewetting effluent. China Leather. 2016:45:26-9.

28. Chen WY, Li GY. Tanning Chemistry (3rd ed). Beijing: China Light Industry Press; 2011. p. 44-46.

29. Nüchter M, Ondruschka B, Bonrathb W, Gumb A. Microwave-assisted synthesis: a critical technology overview. Green Chem. 2004;6:128-41.

\section{Publisher's Note}

Springer Nature remains neutral with regard to jurisdictional claims in published maps and institutional affiliations.

\section{Submit your manuscript to a SpringerOpen ${ }^{\circ}$ journal and benefit from:}

- Convenient online submission

- Rigorous peer review

- Open access: articles freely available online

- High visibility within the field

- Retaining the copyright to your article

Submit your next manuscript at $\boldsymbol{\nabla}$ springeropen.com 